\title{
DIVULGACIÓN CIENTíFICA A TRAVÉS DEL LENGUAJE DEL CóMIC: LA COVID-19
}

\section{Science Popularization through the Language of Comics. COVID-19}

\author{
M. a Blanca MAYOR SERRANO \\ Profesora del Máster Propio en Cómic y Educación de la Universitat de València (España). \\ Correo electrónico: blancamayor@gmail.com
}

Fecha de recepción: 3 de agosto de 2020

Fecha de aceptación: 13 de agosto de 2020

Fecha de publicación: 29 de enero de 2021

\section{Resumen}

Cada vez más entidades públicas y privadas, y, sobre todo, científicos están recurriendo al lenguaje del cómic para hacer llegar a la población general los contenidos más diversos relacionados con el coronavirus SARS-CoV-2 y la COVID-19. En este artículo, además de presentar una selección de cómics, me centro en algunos de los elementos que convierten al cómic en un medio ideal para la divulgación científica, tales como la antropomorfización, las metáforas visuales, los elementos ficcionales, el lenguaje adaptado a un público no experto y a sus necesidades informativas, la oralidad, o los procedimientos reformulativos, así como en la importancia de dominar el medio para que los cómics científico-médicos sean accesibles y atractivos para sus destinatarios.

Palabras clave: divulgación; COVID-19; medicina gráfica; ciencia gráfica; cómic.

\section{Abstract}

More and more public and private institutions, and, in particular, scientists are turning to the language of comics to bring to the general population the most diverse subjects related to the coronavirus SARS-CoV-2 and COVID-19. This paper offers a selection of comics, and focuses on some of the elements that make comics an ideal medium for science popularization, such as anthropomorphism, visual metaphors, fictional elements, language adapted to a non-expert audience and its information needs, spoken language, or reformulation procedures. It also focuses 
on the importance of mastering the medium in order to make scientific-medical comics accessible and engaging for their target audience.

Keywords: popularization; COVID-19; graphic medicine; graphic science; comic.

\section{LA COVID-19, EN VIÑETAS}

Tras la irrupción de la pandemia de la COVID19 en nuestras vidas, no pocas entidades públicas y privadas, y un buen número de científicos -que a veces ostentan la condición de ilustrador - se han lanzado en lo que llevamos de año a informar a la población general, desde distintas ópticas y con objetivos varios, sobre el tema a golpe de viñeta. El noveno arte ha dejado de ser, sin duda, un terreno inhóspito para la comunicación pública de la ciencia y cada vez son más los que se suman al carro de la divulgación científica sirviéndose de la narrativa gráfica. Dignas de mención son las siguientes iniciativas.

Jesús Sánchez, Doctor en Biología Molecular, y Jesús Gil-Pulido, Doctor en Inmunología, han creado recientemente un webcómic ${ }^{1}$ - avalado por la Sociedad Española de Inmunología- que, dividido en tres partes, resume los conocimientos de los que se disponen hasta la fecha sobre la respuesta inmunitaria frente al coronavirus. Así, la primera parte se centra en la respuesta inmunitaria inicial y en cómo se controla la infección en la mayoría de los casos (Foto 1). En la segunda se discute la fase de empeoramiento de los pacientes y cuáles son sus causas inmunitarias. Y la tercera aborda los tratamientos dirigidos a modular el sistema inmunitario

¿Cómo la investigación puede ayudar los pacientes de cáncer con coronavirus?2, también de Jesús Sánchez, es un webcómic de la campaña divulgativa mensual iSuperJ al rescate! La investigación en clave de cómic, puesta en marcha en 2017 por la Fundación CRIS Contra el Cáncer, con sede en Madrid. El objetivo de los veinte cómics publicados hasta ahora, cuyos contenidos son revisados y avalados por el comité científico de CRIS, es dar respuesta a las dudas y preguntas más frecuentes sobre el cáncer, en ocasiones generadas, como explican en su página web, por gran cantidad de mitos y medias verdades ${ }^{3}$.

Concebido más bien para un público infantojuvenil es Coco \& Fran contra el coronavirus ${ }^{4}$ (Foto 2), obra de los dibujantes Nicolás Peruzzo y Alejandro Rodríguez Juele, los creadores del galardonado Bacterias: La historia más pequeña jamás contada ${ }^{5}$. Proyecto de los investigadores del Área de Microbiología del Instituto de Investigaciones Biológicas Clemente Estable (IIBCE) (Uruguay), un microbiólogo del Laboratorio de Microbiología de la Facultad de Agronomía y una viróloga del Laboratorio de Virología Molecular de la Facultad de Ciencias, ambos también de Uruguaya ${ }^{\text {. El material }}$ se compone de dos partes: la historieta propiamente dicha, por un lado, y una guía informativa, por otro. La primera aborda a lo largo de doce páginas y de manera lúdica cómo se transmite el coronavirus SARS-CoV-2, así como la importancia y el porqué de las medidas sanitarias adoptadas. La segunda parte ofrece información relevante y ampliada sobre muchos de los conceptos que aparecen en la historieta.

Paloma Fernández Corcuera, psiquiatra del hospital de Mataró (Barcelona), y Julio A. Serrano, ilustrador de la revista El Jueves, son los artífices de No Panicovid. La guía esencial para vencer el pánico al coronavirus. 1. Saliendo de la $\mathrm{UCl}^{6}$, una guía en formato cómic, publicada en mayo de 2020, destinada a enseñar a los pacientes ingresados por COVID-19 a lidiar con las posibles crisis de ansiedad tras su salida de la Unidad de Cuidados Intensivos. La iniciativa ha contado con el aval científico de

a. Información obtenida de la página web del Instituto de Investigaciones Biológicas Clemente Estable (IIBCE) (Uruguay) http://www.iibce.edu.uy/noticias.htm. 

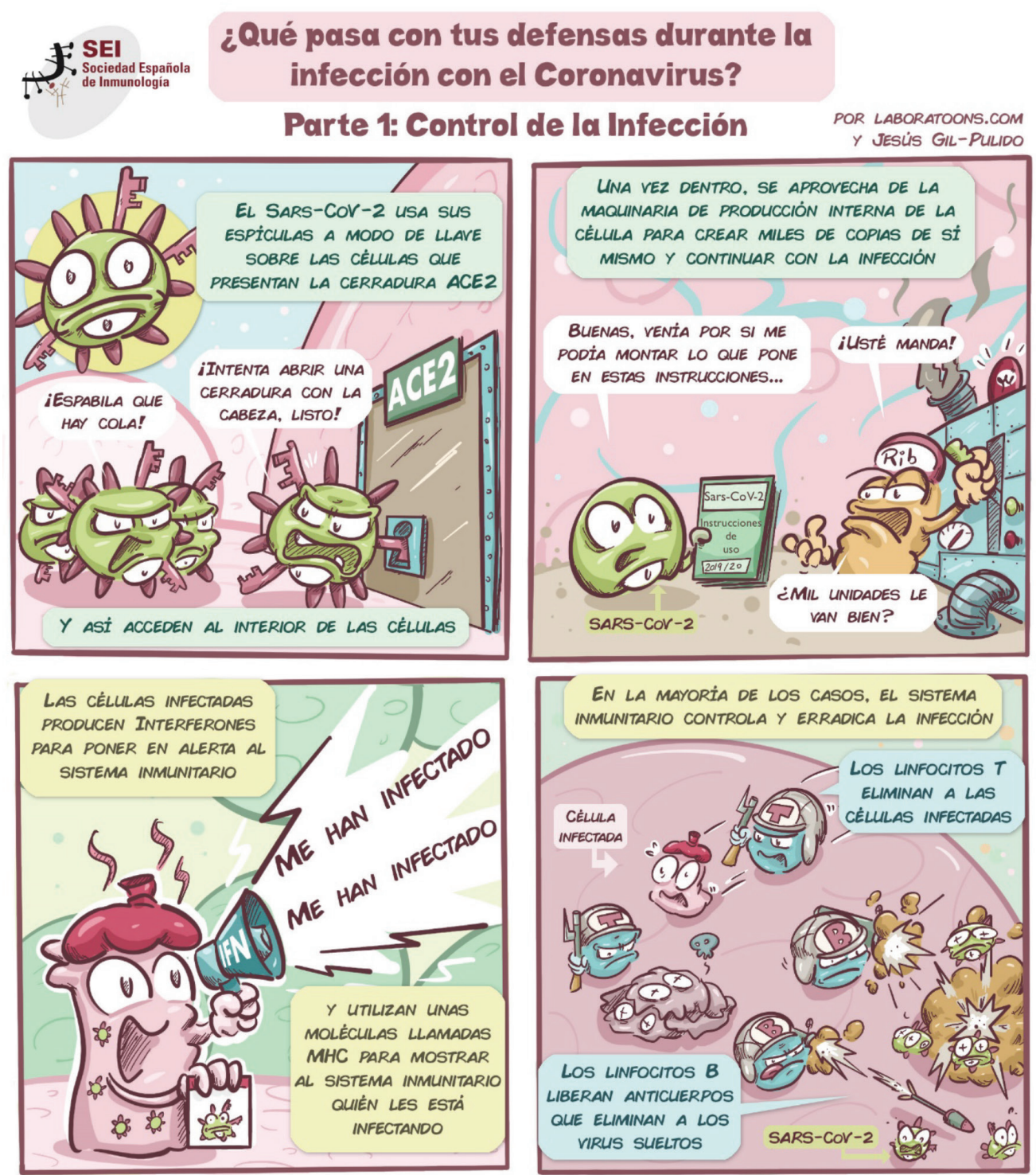

Foto 1. ¿Qué pasa con tus defensas durante la infección con el coronavirus? Parte 1. Cómo funciona la infección. (@ 2020 Jesús Sánchez y Jesús Gil-Pulido). Imagen reproducida con permiso de sus autores.

la Sociedad Española de Psiquiatría, la Sociedad Catalana de Psiquiatría y Salud Mental, y la Sociedad Catalana de Medicina Intensiva y
Crítica, como sus autores indican en la Introducción del material. 


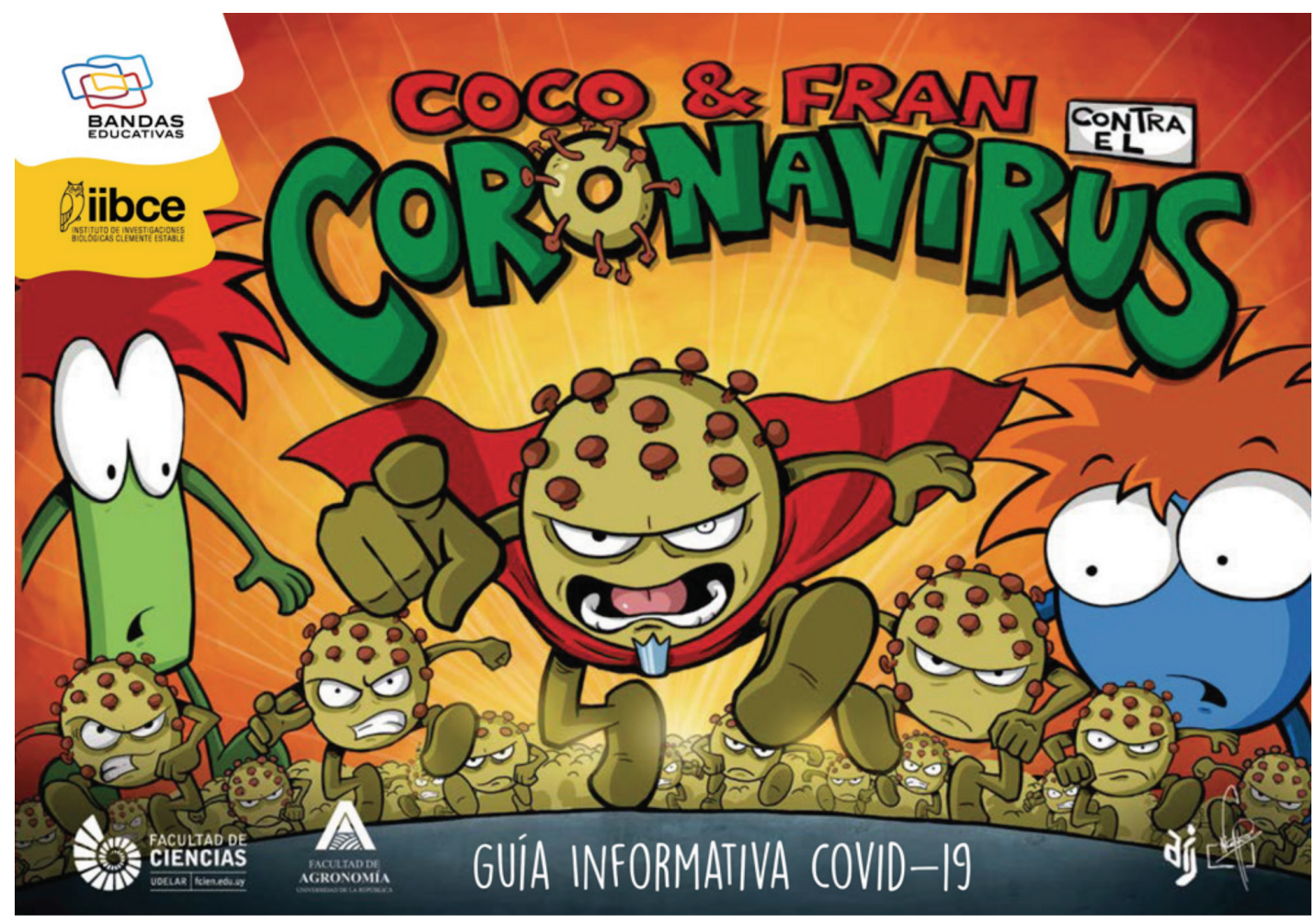

Foto 2. Coco \& Fran contra el coronavirus. (@ 2020 Nicolás Peruzzo y Alejandro Rodríguez Juele, e investigadores del Área de Microbiología del Instituto de Investigaciones Biológicas Clemente Estable, del Laboratorio de Microbiología de la Facultad de Agronomía y del Laboratorio de Virología Molecular de la Facultad de Ciencias). Imagen reproducida con permiso de sus autores.

De qué modo el coronavirus SARS-CoV-2 utiliza nuestras células para replicarse y la importancia de la investigación básica quedan reflejados en el cómic (Foto 3 ) de Miriam Rivera, graduada en Biología Humana, Máster en Comunicación Científica, Médica y Ambiental, y responsable de Biomiics (Biología en cómics).

En una época de bulos, abundan, como era de esperar, las fake news sobre el coronavirus, que alimentan las desinformaciones y las dudas al respecto. A fin de combatirlas, los autores de la web Yo, Doctor, Guido Rodríguez de Lema y
Juan Sanchez-Verde Bilbao -ambos médicos de Urgencias del Hospital Fundación Jiménez Díaz (Madrid) - han creado para la web Maldita Ciencia el Especial coronavirus ${ }^{7}$, una serie de minicómics (Foto 4) que refutan las mentiras en torno al asunto con mucho humor, pero sin perder un ápice de rigor.

Cómics a los que hay que sumar los que nos llegan en forma de traducción. Este es el caso de Un planeta, un desafio ${ }^{8}$, una novela gráfica que narra la historia de la doctora Wendy Hao y su trabajo en primera línea en la $\mathrm{UCl}$ de un hospital de la ciudad china de Wuhan. La traducción 


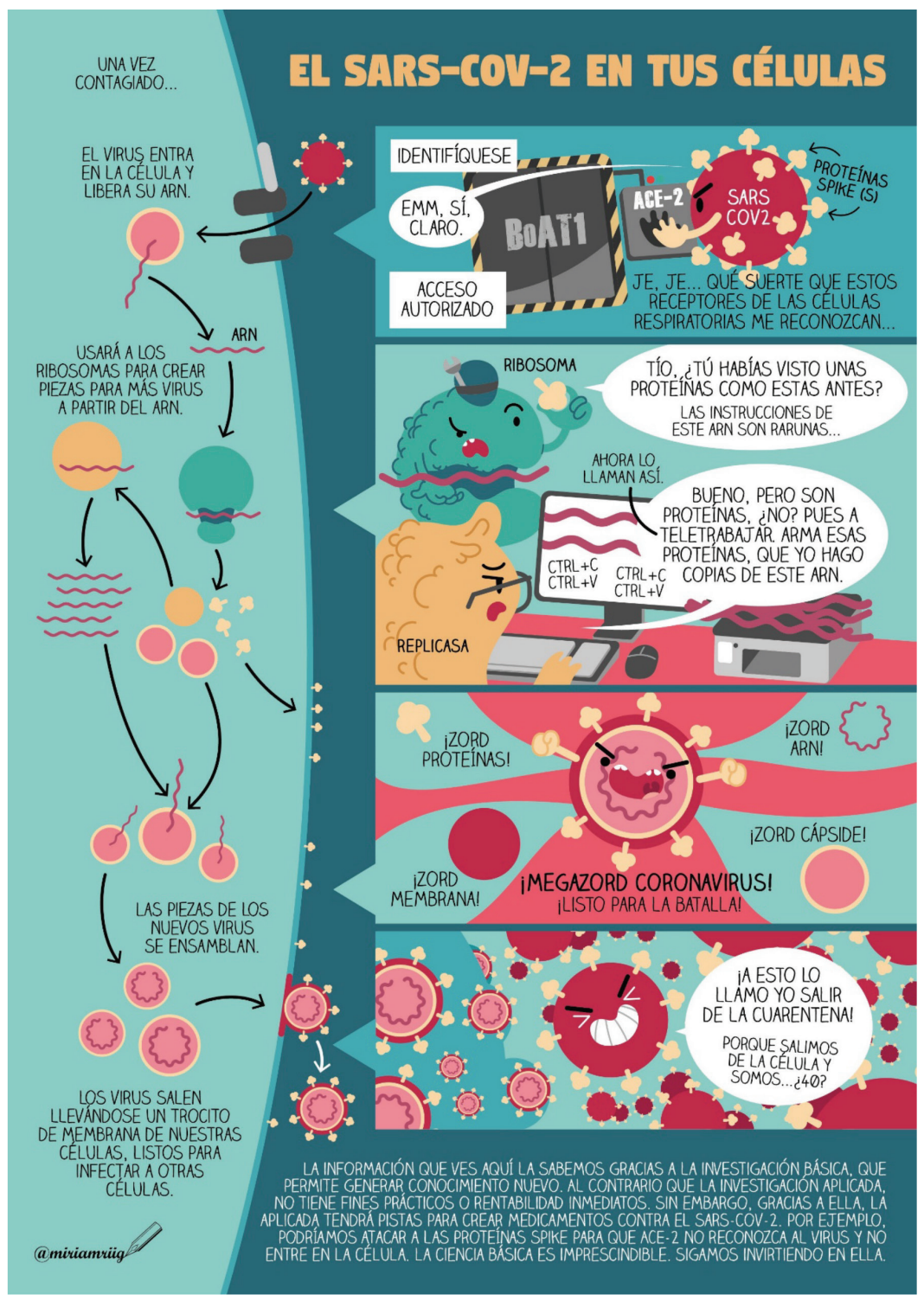

Foto 3. El SARS-CoV-2 en tus células. (C 2020 Miriam Rivera). Imagen reproducida con permiso de la autora.

al español ha corrido a cargo de Juan Antonio Prieto, profesor titular de la Universidad Pablo de Olavide (Córdoba). ¿Sus creadores? Los responsables de la empresa Gen Z Group, de Singapur, que se ocupa de la edición de mangas con fines divulgativos. Esta serie de cómics, que consta de cinco episodios y se ha traducido a numerosos idiomas (alemán, árabe, chino, coreano, español, 

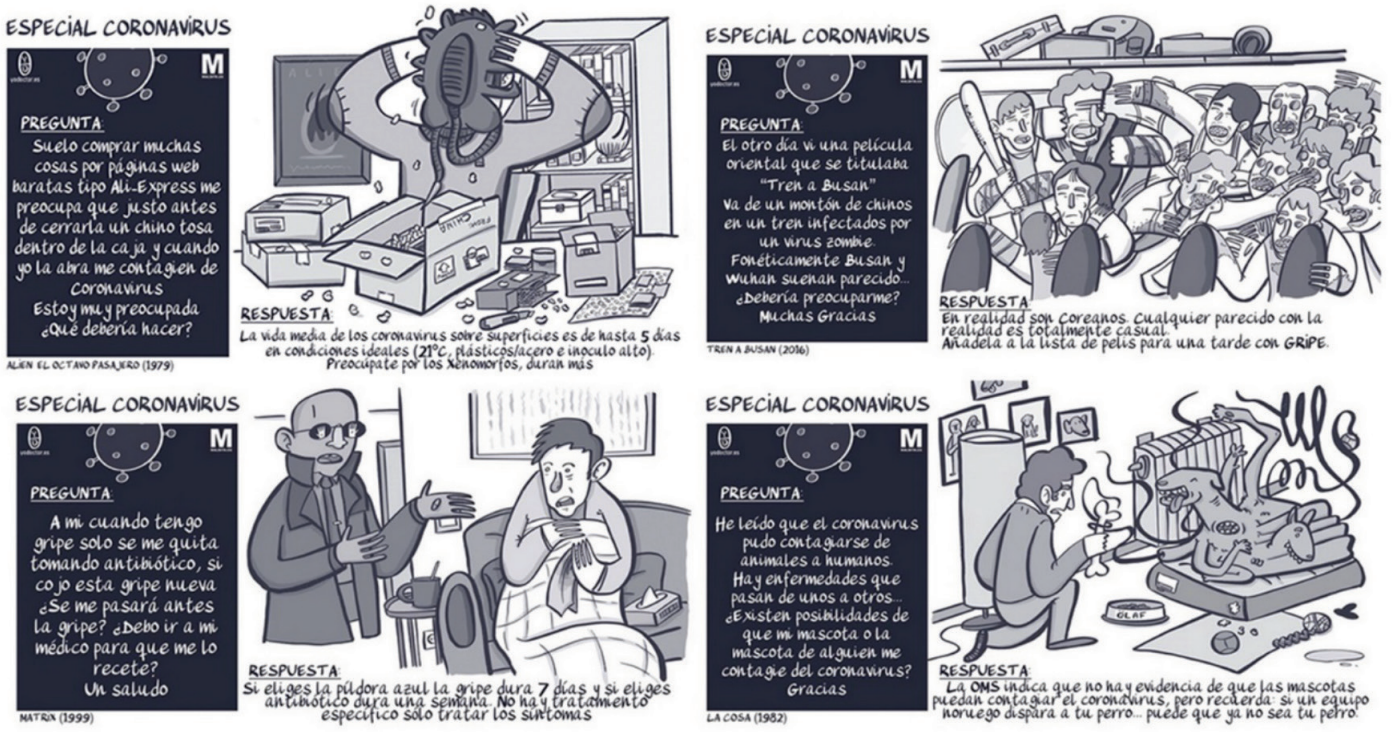

Foto 4. Especial coronavirus. (C 2020 Guido Rodríguez de Lema y Juan Sanchez-Verde Bilbao).

filipino, francés, hindi, italiano, japonés, malayo, portugués, tailandés, tamil, turco y vietnamita), es parte de un proyecto sin ánimo de lucro cuyo principal fin es informar sobre la COVID-19 y el SARS-CoV-2, y concienciar a la población sobre la importancia de la prevención y sobre el tratamiento de esta enfermedad. Se trata de una adaptación del Manual para la prevención y el tratamiento de la COVID-19, el documento de referencia en el abordaje de la enfermedad desde que se tuvo conocimiento de la pandemia en Chinab.

O, por último, Explorando el coronavirus. Un cómic para chicos y chicas ${ }^{9}$, traducción del original inglés Exploring the New Coronavirus. A Comic Just for Kids. Un cómic basado en las entrevistas del corresponsal Cory Turner a Tara Powell, de la Universidad de la Escuela de Trabajo Social de la Universidad de Illinois, Jay Osofsky, del Centro de Ciencias Médicas en Nueva Orleans, y Krystal Lewis, del Instituto Nacional de Salud Mental, sobre lo que los jóvenes podrían querer saber acerca del coronavirus ${ }^{c}$.

Y hasta aquí una muestra de la variedad de cómics que se han editado en español hasta la fecha a raíz de la pandemia covídica, cómics que en distintos formatos y con objetivos diversos nos

b. Información obtenida de la página web Graphic Medicine: https://www.graphicmedicine.org/spotlight-one -world-one-fight/.

c. Información obtenida de la página web de la estadounidense National Public Radio: https://www.npr .org/sections/goatsandsoda/2020/04/01/822540659/solo-para-chicos-y-chicas-un-c-mic-sobre-el-nuevo -coronavirus?t=1596738807559. 


\section{DIVULGACIÓN CIENTÍFICA A TRAVÉS DEL LENGUAJE DEL CÓMIC: LA COVID-19 M. A BLANCA MAYOR SERRANO}

acercan contenidos científicos con magníficas dosis de rigor y entretenimiento ${ }^{d}$.

Llegados a este punto, cabe preguntarse el motivo por el que cada vez más entidades públicas y privadas, y, sobre todo, científicos, están apostando por el lenguaje del cómic para hacer llegar a la población general los contenidos más diversos relacionados con el coronavirus SARSCoV-2 y la COVID-19.

\section{¿POR QUÉ EL MEDIO DEL CÓMIC?}

En realidad, el uso de este medio para la divulgación de la ciencia en general y de temas relacionados con las epidemias y pandemias en particular no es de ningún modo un fenómeno de nuestros días. A título ilustrativo, sirva la exposición Virus y epidemias en el cómic, en la que Manuel Barrero $(2020)^{10}$ ofrece un interesante recorrido - que arranca en la segunda mitad del siglo XVII- por las epidemias y pandemias contadas "tanto en el humor gráfico como en la historieta de formas muy variadas, desde la sátira periodística o el humor infantil hasta el drama o la aventura distópica" (Foto 5) ${ }^{\text {e. }}$

$Y$ es que el cómic, la narrativa gráfica, por sus cualidades tanto en el plano visual -antropomorfización, metáforas visuales, elementos ficcionales, personajes y escenarios de lo más variopinto - como en el textual -lenguaje adaptado al discurso de sus destinatarios, oralidad, llamadas al lector, procedimientos reformulati$\operatorname{vos}^{11-12}$ - , resulta idóneo para explicar conceptos complejos, abstractos y, sobre todo, para implicar al lector ${ }^{13-15}$. Asimismo, permite captar el interés de un conjunto de personas que, de otro modo, no se acercarían a obras asociadas a la divulgación científica, pero que "al estar en forma de cómic, no reciben esa calificación y resultan atractivas para este sector del público" ${ }^{\prime 16}$.

Se trata de un medio que ha demostrado ser muy eficaz para atraer especialmente a un público con un índice bajo de alfabetización científica y a jóvenes con escaso interés en la ciencia ${ }^{17-18}$, así como a la hora de explicar qué son los virus y cómo afectan a nuestra salud ${ }^{19-20}$.

Ahora bien, para que los cómics de corte científico-médico devengan un medio de comunicación óptimo, hay que saber trasladar los contenidos especializados a una narración eficaz, al tiempo que rigurosa, en el plano gráfico y textual; es imprescindible dominar el medio. $Y$, por obvio que resulte, saber adaptar el relato, la historia a la función que se persigue con los cómics - didáctica, educativa o divulgativa ${ }^{f}-\mathrm{y}$ al tipo de lector al que se dirige.

El cómic Esperanza más allá de las grandes expectativas. Historia de las células madre desde su descubrimiento hasta su aplicación terapéutica ${ }^{21}$ es fruto de OptiStem, un proyecto de investigación financiado con fondos europeos sobre células madre que concluyó en 2014 y en el que participaron dieciocho entidades asociadas procedentes de seis países europeos. La versión original se elaboró en inglés, comienza con la historia real de dos niños que presentan graves quemaduras y son tratados con injertos de piel generados a partir de células madre en 1983 . Se adentra a continuación en los éxitos y los reveses de un grupo de

d. Remito al interesado en cómics editados en inglés sobre este campo a la sección "COVID-19 Comics" (https:// www.graphicmedicine.org/covid-19-comics/) del cibersitio Graphic Medicine. También incluye materiales en otros idiomas.

e. Cita tomada del blog de Tebeosfera: https://tebeosfera.blogspot.com/2020/03/virus-y-epidemias-en-el -comic.html.

f. Para un mayor conocimiento de estas funciones, remito al interesado a Mayor Serrano MB. La utilidad del cómic para la formación de traductores médicos. Revista CTPCBA. 2020;145:22-6. Disponible desde: https:// www.traductores.org.ar/wp-content/uploads/2020/04/Rev_145.pdf. 


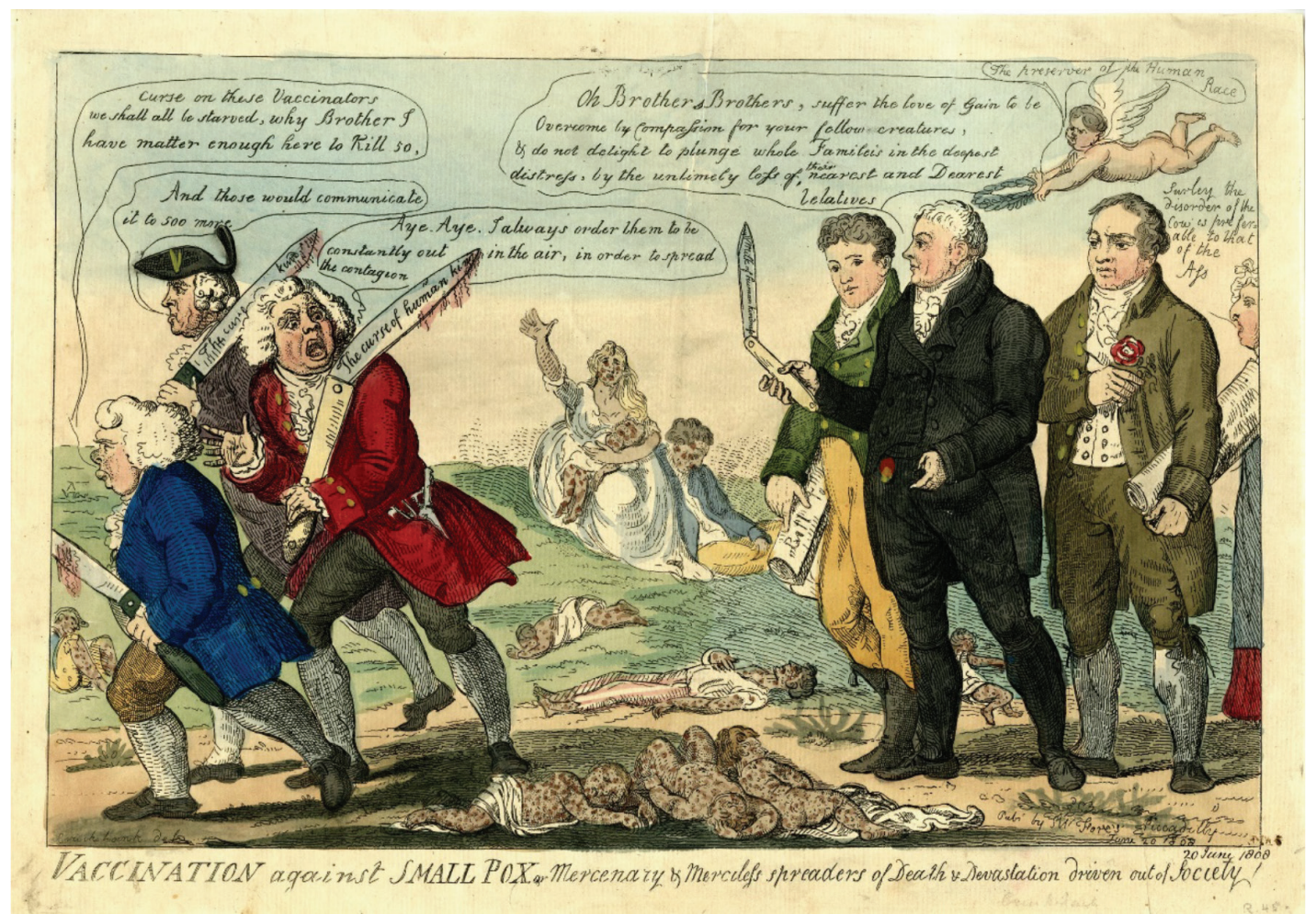

Foto 5. Vaccination against small pox, or mercenary \& merciless spreaders of death \& devastation driven out of society. Isaac Cruikshank. S W Fores Piccadilly. Londres. 1808. (C 1868 The Trustees of the British Museum).

investigadores que trabajan juntos para utilizar células madre para el tratamiento de la ceguera al tiempo que presenta las dificultades relacionadas con la investigación con células madre, incluida la regulación y los problemas éticos. Los investigadores de OptiStem proporcionaron los ejemplos de la vida real de sus investigaciones y experiencias. Cathy Southworth, encargada de dar a conocer la ciencia que se esconde tras la investigación en torno a las células madre, explicaba en mayo de 2012 el porqué de la elección de este medio para la divulgación del proyecto: "[we] needed something eye-catching and enticing; something that would stand out, all the while ensuring that the science was portrayed accurately"g. Lejos de elaborar un material llamativo, atractivo, que invite a su lectura en su totalidad, el cómic no es sino una mera exposición de datos, con ritmo monótono, en la que la información textual se sucede

g. El artículo de Cathy Southworth en el que explica lo que le llevó a adoptar el formato de cómic para la divulgación del proyecto se puede leer en esta página: http://www.insight.mrc.ac.uk/2012/05/29/hope-beyond -hype/\#more-151. 


\section{DIVULGACIÓN CIENTÍFICA A TRAVÉS DEL LENGUAJE DEL CÓMIC: LA COVID-19 M. A BLANCA MAYOR SERRANO}

mayoritariamente en los cartuchos de las viñetas, las cuales de ningún modo contribuyen a una mejor comprensión de lo expuesto, pues poseen tan solo una función estética; es decir, se emplean para ambientar la historia.

Centrándonos en el asunto de este trabajo, cabe detenerse en la historieta -InmunoCoronavirus $^{22}$, iniciativa y guion de Daniel Erlij, reumatólogo del Hospital del Salvador (Chile) y profesor de la Universidad de Chile y de la Universidad Finis Terrae. Según explican en la página web desde la que se puede descargar el material", su objetivo es transmitir "a los más jóvenes la delicada labor del sistema inmune [sic] en esta batalla importante contra el Coronavirus [sic] [...] con un estricto y detallado trasfondo científico". La publicación consta tan solo de seis páginas: portada, la historieta en sí y una página dedicada a explicar lo que el guionista denomina "El sistema inmune". Les invito a que lean el cómic, se detengan especialmente en el título, en la caracterización de los personajes y en las metáforas visuales utilizadas para la explicación de conceptos. Juzguen ustedes mismos si realmente cumple el objetivo que persigue.

Matteo Farinella, doctor en neurociencia y uno de los más destacados defensores y autores de cómics científicos, hacía en 2018 la siguiente reflexión en torno a la necesidad de formación en este campo:

Although they may be easy to read, making good comics requires as much time and skill as making a good documentary. Hence, we also need to train a new generation of science cartoonists who-just like science writers-are able to understand scientific content and translate it into their own unique visual language. At the end of the day, the communication of science in comics will be only as good as the comics themselves ${ }^{23}$.

De ahí la importancia - teniendo en cuenta sobre todo la falta de investigación académica de la que adolece el cómic científico-médico en España y otros países hispanohablantes- de cursos destinados a formar en la elaboración de cómics de este tipo, tales como "Ciencia se escribe con c de cómic"ì impartido desde 2017 por Jesús Sánchez Ruiz, doctor en Biología Molecular, investigador, divulgador y dibujante de cómics científicos, y la bióloga e ilustradora Miriam Rivera Iglesias; el curso de verano "El cómic como herramienta de divulgación y comunicación científica"j, organizado por la profesora Rosario Sabariegos y celebrado en la Facultad de Medicina de Albacete en 2018; o el taller "Cómic e ilustración", impartido por Miriam Rivera Iglesias en el marco del curso teórico-practico "La divulgación científica. Un relato transmedia"k, organizado en 2019 por la Universidad de Murcia. Cursos, en definitiva, indispensables para formar al interesado en el medio y hacer de este tipo de cómic un material riguroso y ameno de divulgación científica.

h. Al material y a la información sobre el mismo se puede acceder desde este enlace: http://www.sochire.cl /ficha. php?id=423.

i. Remito al interesado en este curso a la página web de Jesús Sánchez Ruiz http://www.alymphslife.com /2017/09/el-taller-ciencia-se-escribe-con-c-de-comic/.

j. Remito al interesado en este curso a la página web de la Universidad de Castilla-La Mancha: https://www .uclm.es/noticias/noticias2018/septiembre/albacete/curso_verano_comic.

k. A la información sobre este curso se puede acceder desde este enlace de la Universidad de Murcia: https:// www.um.es/documents/1995586/10366887/LA+DIVULGACI\%C3\%93N+CIENT\%C3\%8DFICA_+UN+RELATO+ TRANSMEDIA+FINAL+2.pdf/4077ac88-25d4-4258-aed9-cd69c7151e71 


\section{DIVULGACIÓN CIENTÍFICA A TRAVÉS DEL LENGUAJE DEL CÓMIC: LA COVID-19 M. $\triangle$ BLANCA MAYOR SERRANO}

\section{REFERENCIAS}

1. Sánchez J, Gil-Pulido J. ¿Qué pasa con tus defensas durante la infección con el coronavirus? Laboratoons [Internet]. 04 de mayo de 2020.

2. Sánchez J. ¿Cómo la investigación puede ayudar los pacientes de cáncer con coronavirus?¡SuperJ al rescate! La investigación en clave de cómic. [Internet]. Madrid: Fundación Cris Contra el Cáncer; 2020.

3. Fundación Cris Contra el Cáncer. iSuperJ al rescate! sale a la calle. [Internet]. Madrid: Fundación Cris Contra el Cáncer. s.f.

4. Peruzzo N, Rodríguez Juele A. Coco \& Fran contra el Coronavirus. Guía informativa de Covid-19 [Internet]. Montevideo: Bandas Educativas/Instituto de Investigaciones Biológicas Clemente Estable; 2020.

5. Peruzzo N, Rodríguez Juele A. Bacterias: La historia más pequeña jamás contada. [Internet]. Montevideo: Bandas Educativas/Instituto de Investigaciones Biológicas Clemente Estable; 2018.

6. Fernández Corcuera P, Serrano JA. No Panicovid. La guía esencial para vencer el pánico al coronavirus. 1. Saliendo de la UCI. [Internet]. s. f.

7. Yo, Doctor. Especial coronavirus. Maldita.es [Internet]. 03 de febrero de 2020.

8. Qu ZG, Liu TC. Un planeta, un desafío. [Internet]. Singapur: Gen Z Group; 2020.

9. Gharib M. Explorando el coronavirus. Un cómic para chicos y chicas [Internet]. NPR. 2020.

10. Barrero M. Virus y pandemias en el cómic. Tebeosfera [Internet]. 23 de marzo de 2020.

11. Mayor Serrano MB. El cómic como recurso didáctico en los estudios de Medicina. Manual con ejercicios [Internet]. Barcelona: Cuadernos de la Fundación Dr. Antonio Esteve no 37; 2016.

12. Mayor Serrano MB. Qué es la medicina gráfica. Tebeosfera [Internet]. 2018:9.
13. Mayor Serrano MB. Cómics, o cómo aprender lenguaje médico a golpe de viñetas. En Estopà $R$ coordinadora. Comunicación, lenguaje y salud. Estrategias lingüísticas para mejorar la comunicación con el paciente. Barcelona: Universitat Pompeu Fabra, Institut de Lingüística Aplicada; 2019, pp. 107-120.

14. Abad Vila M, Mayor Serrano MB. Arrugas (2011) de Ignacio Ferreras. La enfermedad de Alzheimer a través del cómic y del cine. Rev Med Cine [Internet]. 2019; 15(4):237-47.

15. Kearns C, Kearns N. The role of comics in public health communication during the COVID-19 pandemic. J Vis Commun Med. 2020;9:1-11.

16. Sáez de Adana F. La vida imaginaria del científico. El caso del cómic "Los proyectos de Manhattan". Mètode [Internet]. 2004:82.

17. Joubert M. Comics and cartoons are a powerful way to teach kids about COVID-19. The Conversation [Internet]. 07 de mayo de 2020.

18. Spiegel AN, McQuillan J, Halpin P, Matuk C, Diamond J. Engaging Teenagers with Science Through Comics. Res Sci Educ. 2013;43(6):2309-26.

19. Scavone P, Carrasco V, Umpiérrez A, Morel M, Daniela Arredondo D, Amarelle V. Microbiology can be comic. FEMS Microbiology Letters. 2019; 366(14): fnz171.

20. Jee BD, Anggoro FK. Comic cognition: exploring the potential cognitive impacts of science comics. J Cogn Educ Psychol. 2012;11(2):196-208.

21. McLeod K, Hall J, Ross E, Southworth C. Esperanza más allá de las grandes expectativas. Historia de las células madre desde su descubrimiento hasta su aplicación terapéutica [Internet]. Edimburgo: OptiStem Communications; 2012.

22. Erlij D, Nitrox Márquez J, Carvajal K, Docolomansky C. - Inmuno-Coronavirus [Internet]. Chile: Sociedad Chilena de Reumatología; 2020.

23. Farinella M. Science Comics' Super Powers. American Scientist [Internet]. 2018;106(4):218. 


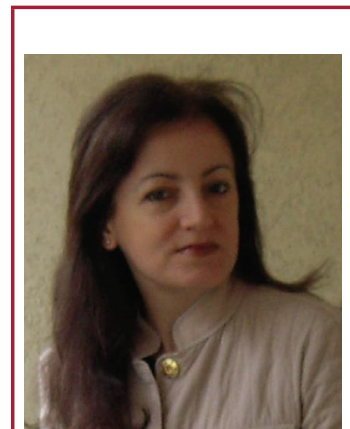

María Blanca Mayor Serrano. Doctora en Traducción por la Universidad de Granada, Máster en Terminología por la Universidat Pompeu Fabra. Profesora del Máster Propio en Cómic y Educación de la Universitat de València. Desde 2011 se dedica a la investigación en torno a la medicina gráfica y a la ciencia gráfica. Y desde 2014 ha dictado varias ponencias sobre la utilidad del cómic para la formación de profesionales sanitarios y la educación para la salud. Es autora del libro El cómic como recurso didactico en los estudios de medicina. Manual con ejercicios. Barcelona: Fundación Dr. Antonio Esteve; 2016, coordinadora y coautora del monográfico Medicina y cómic para la revista Tebeosfera, 2018, y creadora y administradora del grupo de Facebook Medicina y Ciencia Gráfica. 